\title{
Evans, Ricbard J. The Hitler Conspiracies: The Third Reich and the Paranoid Imagination. Allen Lane, 2020, 288 pp.
}

Keywords: conspiracy theories, Nazi Germany, antisemitism

Sir Richard J. Evans, Emeritus Regius Professor of History at Cambridge University and a great expert on the history of the Third Reich, discusses five conspiracy theories in Nazi Germany in the 1930s. Conspiracy theories undermine a (historical) reality in order to reveal a hidden or concealed truth. They presuppose the (covert) actions of a group of people. Evans distinguishes two main variants within conspiracy theories.

The first of these is the conspiracy to achieve world domination, in which the conspiring group (e.g. communists, freemasons, Jews or Jesuits) carry out a series of actions over a long period of time. The Protocols of the Elders Zion is known as the pre-eminent articulation of this first main event in Nazi Germany. According to Nazis, the Protocols contained a blueprint for the establishment of world domination by the Jews. Although a correspondent of the English newspaper The Times, Philip Graves (1876-1953), had already exposed the document as a forgery in 1921, Hitler and Goebbels continued to refer to the Protocols in their propaganda. However, they could hardly use the document from the end of the 1930s, because two judges from Switzerland (Bern) clearly established on the basis of expert testimony that the Protocols were a forgery. Evans devoted the first chapter of his book to this issue.

Evans' second main variant concerns the conspiracy relating to a single event, for which a secret organisation is responsible. Conspiracy theorists believe that important historical events never just happen. They find it even more difficult to accept the idea that an important event can be attributed to a single individual, such as the arson attack on the Reichstag in Berlin on Monday 27 February 1933 by the Dutchman Marinus van der Lubbe (1909-1934). The Nazis thought they were dealing with a communist plot and the communists with a Nazi conspiracy. Evans discusses this conspiracy theory, which 
had far-reaching consequences for the Nazis' position of power from 1933 onwards, in chapter 3 of his book.

Conspiracy theories exclude chance as an explanatory factor in history. This apparently appeals to people because they find it hard to accept that the occurrence of an important event (an assassination attempt, a financial crisis, the outbreak of a war or virus) was 'coincidental'. In addition, Evans also discusses conspiracy theories about whether Germany has suffered World War I by a stab in the back by socialists and Jews in 1918, whether Rudolf Hess flew to Britain to start peace talks with Churchill and whether Hitler escaped from his Berlin bunker after World War II and fled to South America.

Evans shows in his book that conspiracy theories are of all times and that they are extremely persistent, as are the lies and falsifications on which they are based. In-depth research, says Evans, is the only method to determine what is true and what is false. 